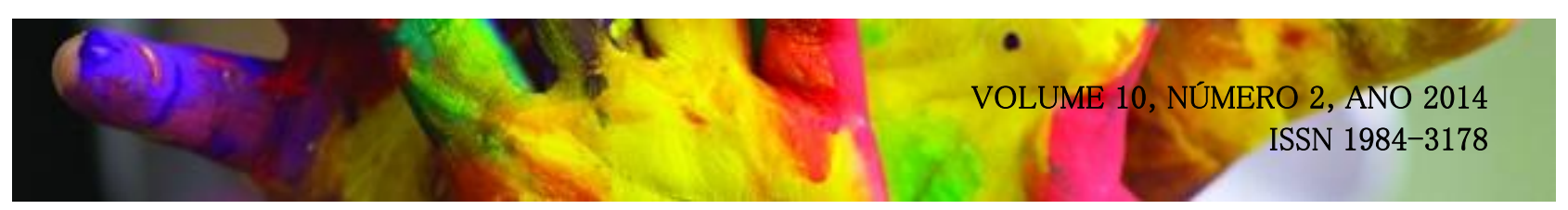

\title{
DEBATES SOBRE CULTURA NO ESPAÇO ESCOLAR: DESAFIOS DO PROFESSOR DE ARTES NAS ESCOLAS PÚBLICAS DE EDUCAÇÃO BÁSICA
}

\author{
DOI: http://dx.doi.org/10.5965/198431781022014050
}

Claudia Carnevskis ${ }^{1}$

\section{RESUMO}

Considerando o debate acerca da cultura uma problemática relevante no contexto da formação de professores de Artes Visuais, analisamos no presente artigo as abordagens metodológicas utilizadas em sala de aula e como as problemáticas que envolvem o tema da cultura podem ser tratadas pelos docentes. A conceituação teórica do trabalho teve como premissa os conceitos apresentados por Terry Eagleton, a partir de seu livro A ideia de Cultura (2011). Acrescentaram-se as referências de Vigotski (2009), Newton Duarte (2003) e Fonseca da Silva (2013) para o constructo de um discurso materialista histórico dialético. Após revisão da literatura, buscamos fontes atuais de debates culturais que pudessem ser objeto de discussão no espaço escolar. Por fim somamos nossas contribuições no que se refere à formação do docente, acrescentando análises sobre as metodologias de ensino mais relevantes quanto ao debate sobre cultura a que tivemos acesso ao longo de nosso trabalho no Curso de Licenciatura em Artes Visuais da Universidade Federal do Amazonas. Nas considerações finais destacamos que o maior desafio para os professores de artes visuais quanto à formação cultural dos discentes é a criação de espaços questionadores e contra hegemônicos dentro de instituições formais de ensino, como em outras

esferas educativas, que possibilitem a apropriação artística, considerando soluções a serem elaboradas levando em conta não apenas as particularidades culturais das comunidades envolvidas, mas as dificuldades encontradas no ensino formal da sociedade capitalista.

Palavras- chave: Ensino de Artes Visuais, Cultura, Formação Cultural, Metodologia de Ensino, Formação Docente.

\section{SUMMARY}

Considering the discussion about culture, a relevant issue in the context of visual arts teacher training, we analyzed at this article the methodological approaches used in the classroom and how

1 Docente do Curso de Licenciatura em Artes Visuais da Universidade Federal do Amazonas - UFAM- Campus de Parintins. Doutoranda do Programa de Pós-Graduação em Artes Visuais da Universidade do Estado de Santa Catarina UDESC, Apoio Fundação de Amparo à Pesquisa do Estado do Amazonas - FAPEAM. Capes, Cnpq e PAP Fapesc 


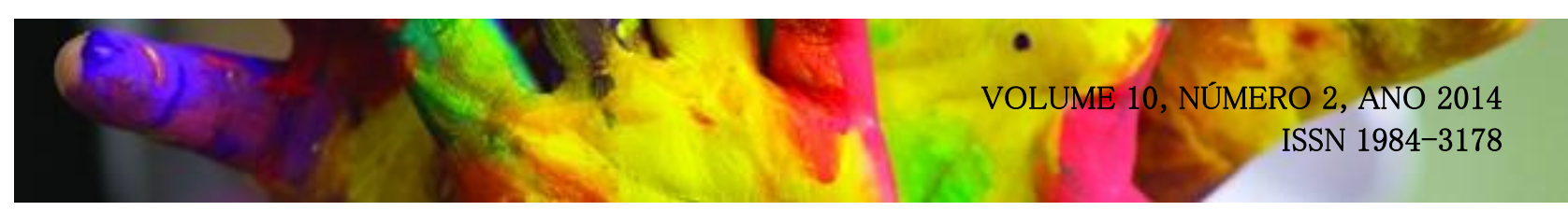

the teachers can talk about the issues arround the culture. The work's theoretical conceptualization had as its premise the concepts presented by Terry Eagleton, from his book A ideia de cultura (2011). In adittion of references from Vygotsky (2009), Newton Duarte (2003) and Fonseca da Silva (2013) for the construction of a historical materialist dialectical discourse. After reviewing the literature we looked for current sources of cultural debate that could be used as a subject for a discussion in the school. By the end, we added our contributions about teaching training, adding analyzes about the most relevants teaching methodologies inside the discussion about culture that we had access over our work in the Bachelor of Visual Arts class at the Federal University of Amazonas. In final thoughts we highlighted that the largest challenge for Visual Arts teachers, talking about cultural formation of the students, is building spaces that question and go against the hegemonic thoughts inside the formal education institutions, as in other educational areas, that makes possible the artistic appropriation, considering solutions that will be elaborated thinking not only in the cultural details of the involved communities, but in the obstacles found at the formal education in the capitalist society .

Key words : Visual Arts Education, Culture, Cultural Training, Teaching Methodology, Teacher Training.

\section{APRESENTAÇÃO}

A conceituação teórica deste artigo teve como premissa os conceitos apresentados por Terry Eagleton, a partir de seu livro A ideia de Cultura (2011), debatido nas aulas da disciplina Educação e Cultura nas Artes Visuais, ministrada pela Prof. ${ }^{a}$ Dra. Maria Cristina da Rosa Fonseca da Silva no Programa de Pós-Graduação em Artes Visuais da UDESC no $2^{\circ}$ semestre de 2014.

Apresentamos neste estudo a necessidade de debater os conteúdos escolhidos pelos docentes de artes visuais para compor o planejamento escolar, sua relação direta e/ou indireta com a comunidade escolar e sua importância na formação cultural. Neste artigo nos debruçamos sobre o conceito de cultura como objeto de estudo na sala de aula e os desafios que o docente de Artes Visuais encontra em sua abordagem metodológica.

Consideramos, nos respaldando em Vigotski (2009), que pautado no materialismo histórico dialético afirma que o desenvolvimento da criança está relacionado à apropriação que esta faz da cultura. Assim, defendemos, em acordo com as teorias do autor, que a criação individual está fundamentada em um modo de produção e participação na cultura e na história, e que o desenvolvimento da criança não é um processo linear e natural e sim uma construção do homem 


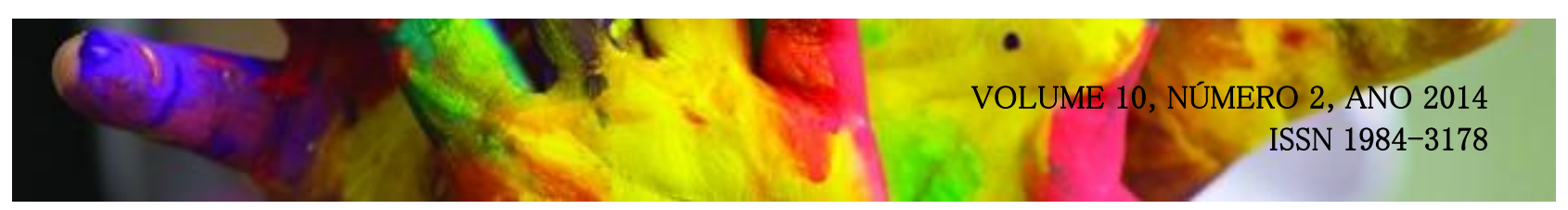

sobre o homem.

Para fomentarmos nossa apresentação sobre o tema, temos como ponto de partida para a ideia de cultura uma dupla recusa: a

do determinismo orgânico, por um lado, e da autonomia do espírito, por outro. É uma rejeição tanto do naturalismo como do idealismo, insistindo contra o primeiro, que existe algo na natureza que a excede e que a anula, e, contra o idealismo, que mesmo o mais nobre agir humano tem suas raízes humildes em nossa biologia e no ambiente natural (EAGLETON, 2011, p. 14).

Isso é importante para a compreensão de nosso ponto de partida, que rejeitará os determinismos biológicos e/ou naturalizadores da cultura, se opondo a uma conceituação que apresente a autonomia do indivíduo como que não sofrendo ação do espaço/tempo que vive.

A consciência de que existe uma correlação de forças na esfera cultural é de suma importância para que o trabalho docente não seja um fazer pedagógico ingênuo e descontextualizado dos processos hegemônicos e contra hegemônicos que envolvem a cultura. Podemos concluir este raciocínio por meio da afirmação de Eagleton (2011, p. 83), de que

Como todas as formas mais efetivas de poder, a alta cultura apresenta-se simplesmente como uma forma de persuasão moral. Ela é, entre outras coisas, uma maneira pela qual uma ordem governante molda para si mesma uma identidade em pedra, escrita e som, e o seu efeito é o de intimidar assim como inspirar.

A persuasão moral, apresentada por Eagleton como uma das formas mais efetivas de poder, também debatida entre outros autores marxistas, encontra terreno fértil no campo escolar. Da formação docente à escolha dos conteúdos didáticos, encontramos um grande número de elementos que são utilizados para modelagem do que se espera de um cidadão.

Ponderando que a estruturação das bases metodológicas da prática docente no que se refere à abordagem sobre os estudos da cultura em sala de aula, em acordo com nossos pressupostos, ela deva ser sensível à cultura que permeia a vida dos estudantes, atentando-se para os pressupostos que envolvem o conceito de cultura como identidade, uma vez que a 


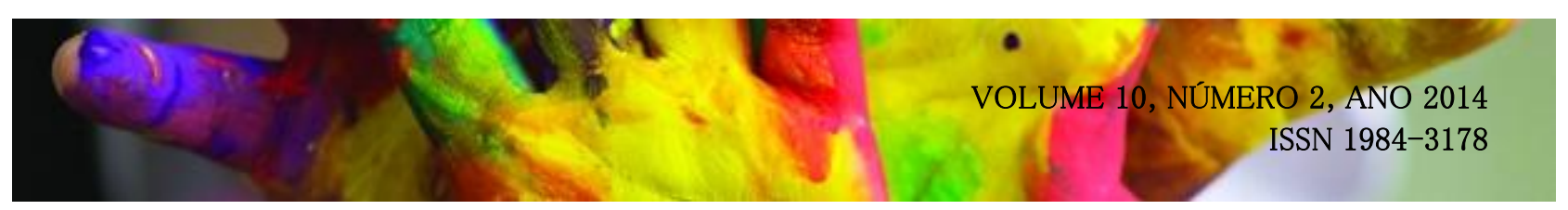

Cultura como identidade é avessa tanto à universalidade como à individualidade; em vez disso, ela valoriza a particularidade coletiva. Do ponto de vista da Cultura, a cultura apodera-se perversamente das particularidades acidentais da existência - gênero, etnicidade, nacionalidade, origem social, inclinação sexual, etc. - e os converte a portadores da necessidade (EGLEATON, 2011, p.84).

Consideramos, ainda, que a prática docente deve ainda ponderar que a apropriação das objetivações do gênero humano (DUARTE, 2003, p. 31) é uma necessidade do próprio processo de formação da individualidade, em que o indivíduo se apropria dos resultados da história. Nesse sentido, a formação cultural dos estudantes, principalmente a que ocorre no espaço escolar, merece destacada atenção por parte do professor de artes.

Antes que seja possível um debate crítico sobre cultura e arte no espaço escolar, é imperativo que as elaborações acima elencadas como basilares sejam ofertadas durante a formação dos futuros professores. Concordamos que para isso seja necessário

um investimento na formação em Artes Visuais com vistas a sedimentar uma práxis criadora e, a partir de um olhar histórico crítico, sedimentar bases para um processo de conhecer a realidade escolar, estabelecer relações desse contexto com a sociedade, reconhecer a arte como produção humana e sistematizar processos educacionais que possibilitem a formação de sujeitos preparados para, a partir da arte, intervir em seu meio social. Neste processo, a avaliação é parte das etapas de pesquisa, reflexão e ação, como método de problematizar a realidade (FONSECA DA SILVA, 2013, pág. 23).

Desta defesa iniciamos nosso debate, considerando que a problematização da realidade perpassa pelo aprofundamento da inserção dos conceitos que abrangem a temática cultural em sala de aula e será pautado pelos aspectos teóricos e metodológicos desenvolvidos pelo docente, que por sua vez devem estar embasados em uma formação docente de qualidade, que reforce os processos de pesquisa, reflexão e avaliação de forma crítica.

\section{A formação do docente em artes visuais: teoria e prática a caminho do debate sobre}

\section{cultura}

Neste artigo propomos aos professores da área de artes a superação do discurso do pós- 


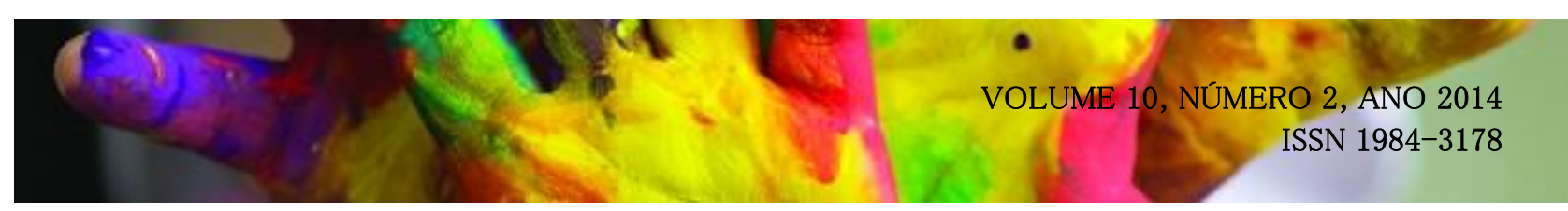

modernismo, aqui compreendido como um particularismo universalizado ${ }^{2}$, considerando, nas palavras de Eagleton (2011, pág. 114-115):

Uma razão pela qual o pós-modernismo parece persuasivo é que ele promete evitar as piores facetas tanto da Cultura como da cultura $^{3}$ ao mesmo tempo que preserva suas qualidades mais atraentes. (...) Como a cultura como modo de vida, ele celebra o particular, embora um particular que é mais provisório do que enraizado, mais híbrido do que um todo. Contudo, já que o pós-modernismo afirma o popular e o vernáculo onde quer que os encontre no globo, combina o seu particularismo com certa indiferença altiva ao lugar. Suas simpatias populares nascem mais de um ceticismo quanto a hierarquias do que, como no caso da cultura como solidariedade, de um compromisso com os expropriados. Seu igualitarismo é tanto um produto da mercadoria como uma resistência a ela.

A regência de disciplinas de graduação relacionadas diretamente à formação do docente de Artes Visuais, assim como nossa própria experiência docente em escolas públicas, contribuiu para que tecêssemos algumas elaborações acerca dos entraves para a construção de um pensamento contra hegemônico e crítico que fortaleça os debates culturais tanto no espaço universitário quanto nas escolas de educação básica, forçando um questionamento quanto à apresentação da cultura como produto da mercadoria e seu viés contestador.

Admitimos existir um distanciamento entre as teorias apresentadas nas salas da universidade no curso de licenciatura em Artes Visuais e as práticas relatadas pelos estudantes da durante avaliações das atividades de observação, coparticipação e regência de sala de aula nas instituições públicas de ensino de Parintins, situada no estado do Amazonas, nas disciplinas de estágio supervisionado obrigatório. A formulação da afirmação do distanciamento da teoria apresentada no campo acadêmico e a prática escolar é reforçada pelas apresentações que faremos a seguir, diante de estudos de outros autores e se sobressai não apenas pela simples escolha de conteúdos, formulação curricular e discurso didático pedagógico, mas é perceptível diante do distanciamento entre as necessidades das equipes escolares e as políticas públicas oferecidas pelos governos municipais e estaduais.

Na cidade de Parintins, em que desenvolvemos nossas experimentações no campo de nossa docência universitária, apenas um dos professores que tivemos contato que lecionava a disciplina de Artes Visuais era formado nesta licenciatura. Costumeiramente as secretarias municipal e estadual

\footnotetext{
2 EAGLETON, 2011, pág. 115.

3 Cultura com C maiúsculo, segundo Eagleton, está associada aos status da política, associada ao poder.
} 


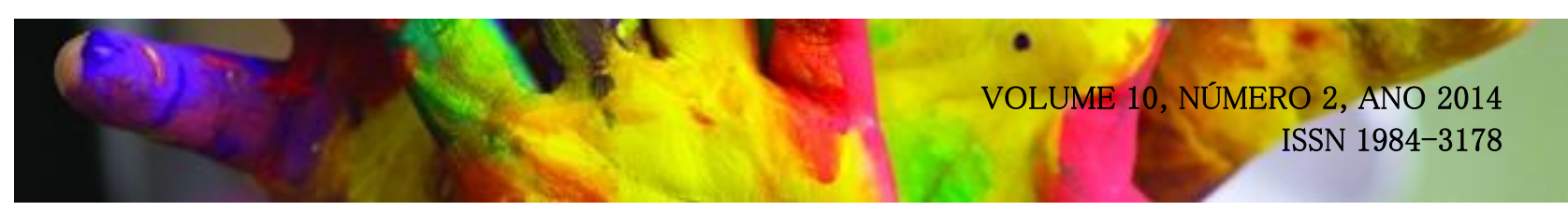

de ensino delegam a disciplina de artes como uma maneira de complementar a carga horária dos professores de outras áreas. Curiosamente as disciplinas de artes de grande parte das escolas que acompanhamos são oferecidas nos dois últimos horários de aula às sextas-feiras, o que nos faz supor que existam diversos profissionais que administram a disciplina, o que torna muito mais complexo pensar em uma estruturação pedagógica do ensino de artes nas redes públicas de ensino.

Com a formação da primeira turma do curso de licenciatura em Artes Visuais da Universidade Federal do Amazonas (UFAM) do Campus de Parintins (anteriormente o estado oferecia apenas um curso de licenciatura em Artes Visuais na modalidade presencial, no campus de Manaus da UFAM), esperamos que o cenário se modifique, com a efetivação de um quadro docente específico da área de artes nas escolas do município e região. Nesta medida, também será possível desenvolver pesquisas que verifiquem o impacto da inserção destes profissionais nas escolas públicas da região.

$\mathrm{Na}$ análise do ementário disponível no Projeto Pedagógico do Curso de Licenciatura em Artes Visuais - ICSEZ/UFAM verificamos que doze das disciplinas oferecidas pelo curso apresentam referências teóricas críticas. No entanto é necessário um estudo futuro e aprofundado para verificarmos em que medida as leituras, debates e atividades de ensino, pesquisa e extensão oferecidos segundo pressupostos críticos foram suficientes para uma formação condizente com o perfil docente que apresentamos neste artigo.

Tanto no que se refere à formação docente, quantos às políticas públicas e aspectos didático e metodológicos dos currículos escolares, neste caso com relação aos estudos sobre cultura, é necessário compreender os processos hegemônicos, conceituando que, segundo Raymond Williams

a hegemonia supõe a existência de algo verdadeiramente total, não apenas secundário ou superestrutural, como no sentido fraco da ideologia, mas que é vivido em tal profundidade, que satura a sociedade a tal ponto que, como Gramsci coloca, constitui mesmo a substância e o limite do senso comum para muitas pessoas sob sua influência, de maneira que corresponde à realidade da experiência social muito mais nitidamente do que qualquer noção derivada da fórmula de base e superestrutura. Pois se a ideologia for apenas um conjunto abstrato e imposto de noções, se as nossas ideias, pressupostos e hábitos sociais, políticos e culturais forem meramente resultado de uma manipulação específica, de um tipo de formação aberta que pode ser simplesmente encerrado ou removido, então seria muito mais fácil mover ou alterar a sociedade do que na prática sempre foi ou é. (2001, pág. 5152) 


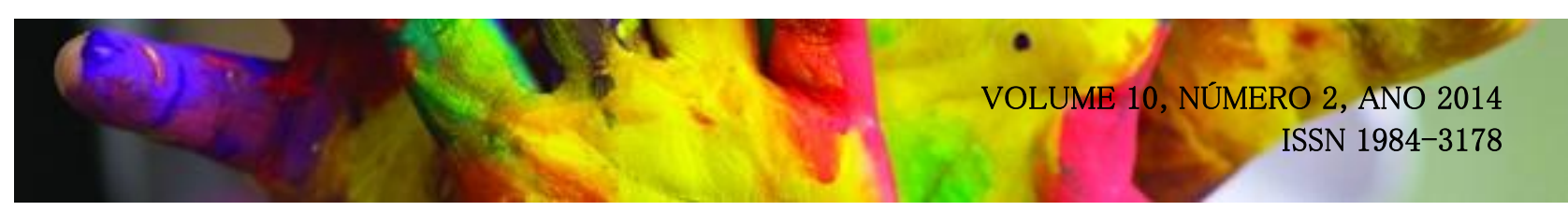

A hegemonia no campo do ensino escolar se apresenta de forma mais aberta que no campo da cultura, ao compararmos as apresentações acima demonstradas no que se refere à cultura que utiliza os preceitos pós-modernos do particularismo universalizado.

Além da dificuldade em se traçar em que medida o aparato teórico influencia na formação, e em quem medida é possível uma educação que supere a lógica do capital da simples formação humana para o mercado de trabalho, é necessário um investimento em ensino, pesquisa e extensão que valorize a qualidade e impacto do trabalho da universidade nas comunidades atendidas e na visualização de como os conceitos hegemônicos alcançam as demonstrações culturais mesmo quando estas estão ilustradas em discursos de profusão de subculturas.

Esta profusão de subculturas, segundo Eagleton (2011, pág. 66) tem como resultado

\begin{abstract}
Um conformismo pluralizado, no qual o universo único do iluminismo, com a sua auto identidade e lógica coercitiva, é desafiado por toda uma série de mini mundos exibindo em miniatura quase as mesmas características (...). Enquanto isso, o sistema político dominante pode criar coragem com o fato de que não tem apenas um oponente, mas uma coleção heterogênea de adversários desunidos. Se essas subculturas protestam contra as alienações da modernidade, também se produzem na sua própria fragmentação.
\end{abstract}

Sendo assim, podemos considerar que, embora essa disseminação de subculturas se paute em um enunciado libertário, sua prática pode ser tão defensora dos valores hegemônicos quanto as políticas públicas defendidas por estes.

\title{
Desafios dos debates culturais em sala de aula
}

Para esta análise apresentamos inicialmente duas abordagens didático-metodológicas antagônicas e pouco eficientes, do ponto de vista dos autores que aqui representam nossas premissas, para os debates culturais em sala de aula. Avançaremos na discussão trazendo um artigo que gerou polêmica por considerar os aspectos educativos do Funk e traçaremos algumas contribuições quanto aos aspectos hegemônicos e contra hegemônicos da cultura e o papel do professor de artes diante deles.

Das abordagens metodológicas que consideramos menos eficientes, do ponto de vista dos autores aqui tratados e considerando as avaliações feitas anteriormente, a primeira se trata daquela que não leva em consideração as condições de vida e experiências dos estudantes (VIGOTSKI, 


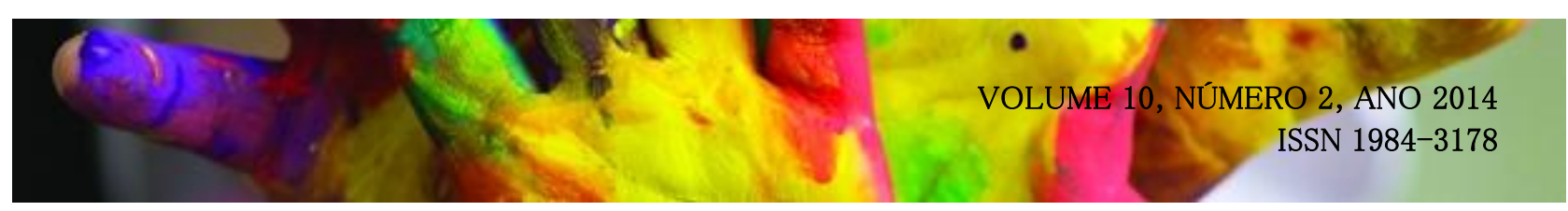

2009), menosprezando a cultura em que a comunidade está inserida.

Como podemos iniciar um debate acerca de cultura negando o que os jovens têm como realidade? Não raro encontramos estudantes da educação básica que dizem não ter nenhum apreço pela disciplina de artes oferecida na escola, em contrapartida observamos que grande parte deles têm os cadernos repletos de desenhos, se encontram para dançar com os amigos e não se separam de seus fones de ouvido.

Este abismo que separa o que se debate enquanto cultura em sala de aula e o que se vive no mundo real é o primeiro entrave para o debate de conceitos ligados à cultura em sala de aula. Como pode ser possível debater a cultura, seja sob um prisma multiculturalista ou crítico, se as representações culturais dos estudantes não forem primeiramente debatidas? E, diante dessa disparidade, como adentrar o campo da arte com estudantes que não conseguem avaliar a própria produção ou consumo artístico?

A cultura ou mundo real dos estudantes é tema recorrente das reuniões pedagógicas escolares, fazendo parte de grande parte das apresentações dos Projetos Político Pedagógicos das instituições de ensino, o diagnóstico da comunidade escolar ou o perfil da clientela, embora as elaborações sobre a cultura da localidade muitas vezes estejam restritas a constatações econômicosociais que não repercutem na introdução dos conteúdos pedagógicos.

A segunda abordagem metodológica, considerada em nossas avaliações como sendo contraproducente, é por outro lado, a que toma apenas a cultura da comunidade como referência para o debate. Afinal, mais preocupante que trazer conceituações e reflexões sobre culturas alheias sem antes debater a própria realidade é reduzir a tarefa do docente de artes a uma reprodução passiva daquilo que o estudante já tem acesso além dos muros da escola.

O preenchimento das disciplinas de artes com a reprodução em sala de aula das pressões artísticas e culturais da região da escola é justificado como sendo uma demonstração de respeito e reconhecimento da cultura local. Há de se assumir que o tensionamento disciplinar (neste sentido empregando o disciplinar como um sinônimo para comportamental e adequação dos estudantes às regras de convivência da instituição escolar) diminui na medida em que a escola se confira como uma ampliação do cotidiano discente. É confortável do ponto de vista das possibilidades de aproximação na relação professor-aluno, mas o empobrecimento do conteúdo curricular se faz mais 


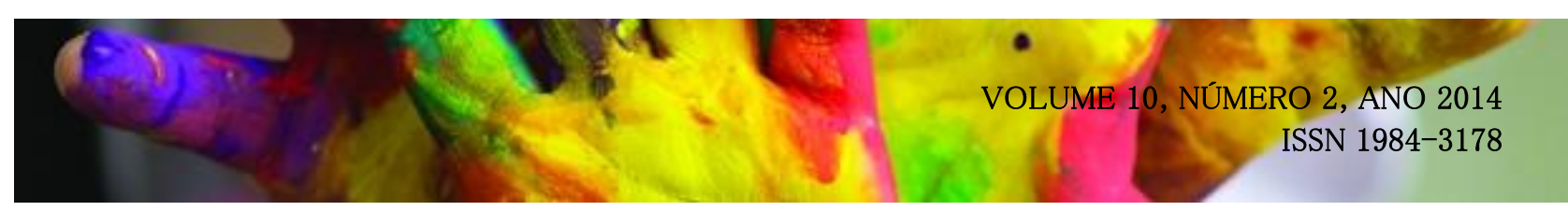

presente neste tipo de trabalho pedagógico.

Em oposição a esta linha de raciocínio, defendemos o posicionamento de Duarte (2003, p.77-78), em que

Assim como a concepção pedagógica de Dermeval Saviani, também a psicologia vigotskiana apoia-se no método dialético de Marx, em cujo âmbito não há margem nem para o evolucionismo ingênuo (seja no plano da história da organização social humana, seja no plano da história do conhecimento), nem para o relativismo que nega a existência de formas mais desenvolvidas de vida social e de conhecimento como apropriação da realidade objetiva pelo pensamento.

O autor contrapõe-se ainda aos ideários pedagógicos contemporâneos que "frequentemente concebem o processo educativo como um processo de interação entre significados subjetivos e individuais em oposição a um saber objetivo socialmente construído" (2003, p. 78). Neste sentido observamos a necessidade de superar o evolucionismo e relativismo rumo a um processo educativo libertador.

Nossas apresentações se centram no esforço de evitar que o professor de artes se torne mais um a reforçar a divisão da classe trabalhadora de forma preconceituosa e estereotipada. A justificativa de reforço das representações hegemônicas se alicerça na teoria de que a cultura e a arte sejam temas subjetivos, respaldando a abordagem metodológica que trabalha apenas com o material artístico-cultural dos estudantes numa concepção muito aceita pós-moderna de que o efêmero e o multicultural fomentam a diluição dos conceitos. A efemeridade é marca registrada da cultura pósmoderna, centrada num individualismo de muitos selfies ${ }^{4}$. O reforço de milhares de compartilhamentos em redes sociais e pouca reflexão sobre as informações registradas, reforçando a constatação de Jameson (1996), de que o pós-modernismo é a lógica cultural do capitalismo tardio.

Nossa avaliação considera que a ausência de pesquisa prévia e debate na formação docente acerca do papel da cultura no contexto escolar é um quesito a ser mais considerado neste caso do que uma postura conscientemente pós-moderna. Um exemplo do que discutimos é que a partir das avaliações, debates e relatórios apresentados pelos estudantes do curso de licenciatura verificamos que o período de abril marca (em escolas de sul a norte do país) uma abordagem da cultura indígena de forma superficial e estereotipada. Mesmo escolas que atendem crianças vindas das áreas

\footnotetext{
4 Expressão trazida da língua inglesa utilizada para autorretratos geralmente feitos por telefones celulares para postagem nas redes sociais.
} 


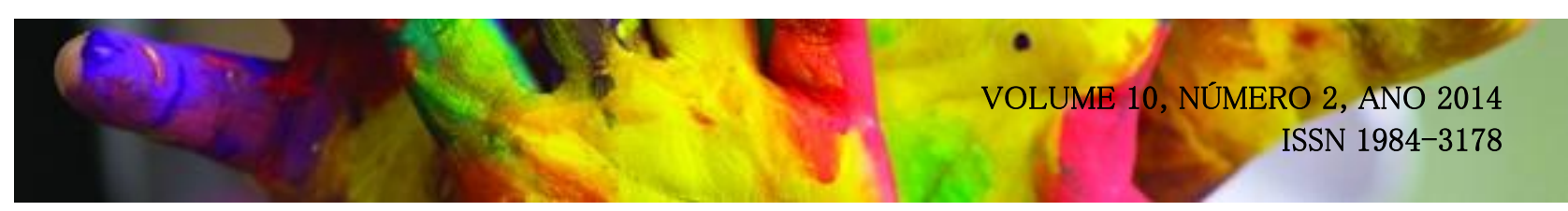

indígenas mantêm em seus calendários o dia do índio como um evento festivo, esvaziado de crítica.

A utilização - como ponto de partida e não o ponto de chegada - das experiências vividas pelos estudantes deve concentrar-se em estabelecer, diante de um debate possível no ambiente escolar, os aspectos positivos e negativos, inclusive apresentando a apropriação que a indústria cultural faz das expressões artístico-culturais que constituem a cultura da comunidade.

Diante dos estudos acerca do desenvolvimento do trabalho docente com a cultura juvenil das escolas públicas, nos deparamos com um artigo que gerou polêmica no espaço virtual de notícias. O artigo apresentado por Silva (2014), que faz parte de sua dissertação do Mestrado em Educação pela Pontifícia Universidade Católica de São Paulo (PUC-SP), foi exposto na XI Semana da Mulher da UNESP de Marília e aceito em uma conferência na Universidade de Columbia. Intitulado "Só mina cruel: Algumas reflexões sobre gênero e cultura afirmativa no universo juvenil do funk" foi alvo de duras críticas no espaço virtual e, mais do que o artigo, nos causou extrema curiosidade quanto ao posicionamento dos comentários no site de notícias.

Afinal, o que chocou os leitores foi o estudo sobre o funk, a apresentação no exterior de um elemento da cultura brasileira que não é motivo de orgulho para muitos ou o fato de se debater o funk na sala de aula? Os comentários apresentados na página podem representar não apenas o modo como o funk é marginalizado, mas como são representados os jovens que absorvem esse estilo. São estes jovens que preenchem as vagas das escolas públicas. Interessa-nos compreender como eles absorvem outras culturas, mas devemos nos atentar, enquanto professores, às representações que o senso comum impõe sobre eles. Em outras palavras não basta apenas conhecer as culturas alheias a minha e a dos estudantes a que leciono, mas também é necessário compreender como somos representados por outros setores da sociedade.

O artigo de Silva (2014) tem como objeto central a racionalidade tecnológica e a cultura afirmativa como indicativo da formação dos indivíduos. Inclui apontamentos sobre a Teoria Crítica da Sociedade e os conceitos de formação, cultura afirmativa e racionalidade tecnológica, contendo a descrição do procedimento de coleta de dados e análise do material e algumas reflexões sobre as relações de gênero no interior das experiências juvenis da classe popular com embasamento teórico de Herbert Marcuse, Max Horkheimer e Theodor W. Adorno.

A autora reconhece que o Funk é mais um dos produtos resultados da cultura afirmativa, em 


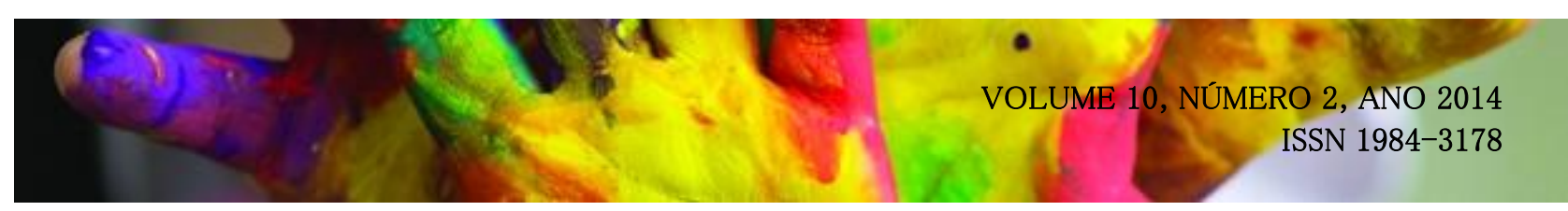

que a lógica da racionalidade tecnológica da industrialização torna produto a cultura de massa. Assim, o funk, como não poderia deixar de ser, apresenta os elementos ideológicos presentes em nossa sociedade (SILVA, 2014).

Silva (2014) afirma que, embora concorde que o discurso das letras de funk seja de reprodução da opressão e dominação da mulher na sociedade, a tarefa que se abre é a de construir um diálogo permanente com as novas gerações segregadas nos guetos pobres dos centros urbanos, sendo que o funk pode ser utilizado para dar voz às mulheres em uma desalienação da relação do indivíduo com seu corpo e sexualidade, principalmente no que se refere ao gênero feminino.

Embora nos falte embasamento para uma conclusão para uma avaliação de quanto o funk pode ou não ser utilizado em sala de aula no sentido de mobilizar os estudantes para o debate apresentado por Silva(2014), ainda que nos sobrem dúvidas acerca do poder de empoderamento que seja possível proporcionar por meio deste, é necessário que se pense acerca da sua utilização, mesmo que como forma de iniciar os debates sobre cultura.

Deparamos-nos com a necessidade de se pensar no conceito de subculturas apresentado por Eagleton (2011) para refletir em que medida o funk realmente pode ser libertário em uma utilização pedagógica/cultural. Ainda, em acordo com o autor, s deparamos com o questionamento do quanto a Cultura como identidade, já apresentada neste texto quanto à sua aversão a universalidade e a individualidade não são levantadas como uma bandeira de transformação e empoderamento sem que estes conceitos sejam na realidade debatidos. Ao mesmo tempo em que visualizamos a ausência de uma identidade cultural que possa criar uma noção de solidariedade (ao menos) entre os indivíduos que estão à margem da sociedade (ou do que ela diz ser o padrão de comportamento aceito).

Para reforçar nossas elaborações neste campo de estudo, apresentamos nossa análise sobre uma matéria disponibilizada no meio digital pelo Grupo Folha de São Paulo - Uol, intitulada "Pichador morre após cair de prédio no Centro de São Paulo" (2014). Verificamos que os comentários seguem o raciocínio de senso comum apresentado na matéria que debate o artigo de Silva(2014). Ali representados estão os grupos que avaliam e marginalizam os adolescentes das camadas populares.

As manifestações proferidas no espaço destinado aos comentários dos leitores do jornal 


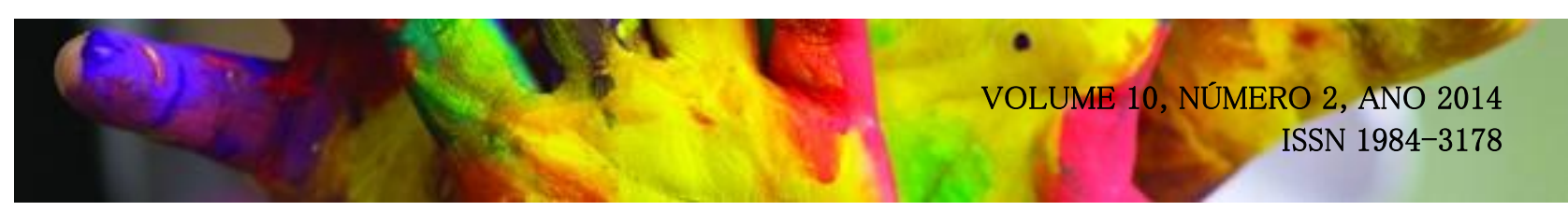

digital eram quase que na totalidade de satisfação com a morte de um jovem de periferia que interfere com seu grupo no espaço urbano que oficialmente, na lógica de manutenção de status quo deveriam se manter sem voz ou representação, (à exceção, é claro, do grafite que foi apropriado pelo comércio de arte e que se enquadra no padrão estético da elite). É este senso comum que referenda o juízo de valor de uma parcela de professores, parcela esta que exclui dos debates culturais aquilo que julga ser inconveniente enquanto objeto de análise cultural.

\section{Considerações Finais}

Neste artigo apresentamos o conceito de cultura como objeto de estudo na sala de aula e traçamos alguns dos desafios que o docente de Artes Visuais encontra em sua abordagem metodológica, apontando as necessidades de uma formação docente que contemple o desenvolvimento sobre o debate cultural. Tecemos nossas contribuições a partir de um embasamento materialista, histórico dialético, formulando questões surgidas de avaliações da prática docente. Não faz parte de nossas ambições encerrar o assunto ou trazer respostas prontas para o que seja uma prática docente que colabore com o processo contra hegemônico de cultura, mas suscitar o debate para novos estudos principalmente em nossa área de pesquisa, que se baseia nos estudos acerca da formação de professores de Artes Visuais da região norte do Brasil.

No que se refere aos debates culturais em sala de aula, constatamos que existem três estudos necessários. O primeiro no que se refere à formação docente no sentido de reforçar no ensino, pesquisa e extensão o conceito de cultura e temas relacionados. O segundo estudo necessário se refere à criação de políticas públicas que reforcem os debates culturais (neste aspecto ressaltamos os desafios encontrados em se pensar políticas governamentais que consigam atender as premissas apresentadas neste estudo, uma vez que consideramos que o estado mantém, em grande parte das políticas de governo os aspectos hegemônicos de dominação cultural). O terceiro estudo é o que se dedica à compreensão dos aspectos didático e metodológico dos currículos escolares.

Neste sentido utilizamos as teorias apresentadas por Reis (2014) que, concordando com Frederic Jameson, relata ser possível exercer uma contra hegemonia autêntica por meio da arte, afirmando que ainda existem produções culturais não totalmente contaminadas pela fantasmagoria da mercadoria. Mas reconhece, ainda em conformidade com as teorias de Jameson, que "o grande 


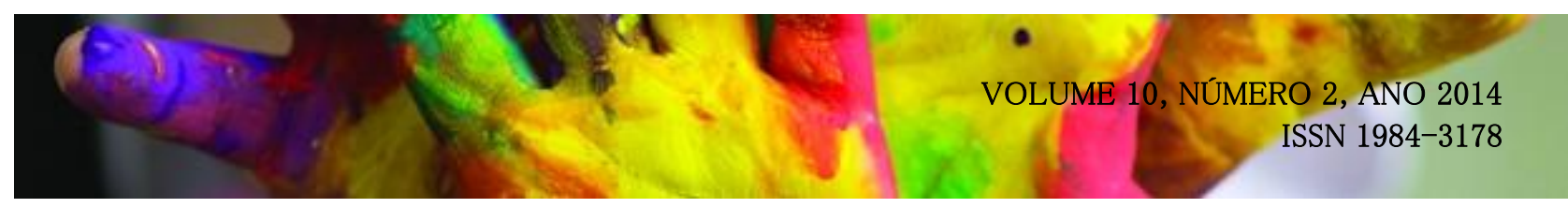

desafio colocado para o artista e intelectual marxista é buscar intensamente formas de exercer a resistência por dentro do sistema sem que isso signifique deixar-se cooptar por ele". Defendendo a "utilização da alegoria como esquema interpretativo para forçar a expansão de determinados temas circunscritos aos valores e crenças burgueses” (Reis, 2014).

A partir deste raciocínio podemos concluir que a tarefa docente também pode encontrar, a partir desse exercício contra hegemônico da arte, uma base para o debate cultural que crie formas de resistência aos processos de dominação.

Consideramos que a prática docente, principalmente daquele que se dedica ao ensino das artes visuais, deva proporcionar uma formação cultural que compreenda a assimilação das objetivações do gênero humano (DUARTE, 2003, pág.31) como uma necessidade do próprio processo de formação da individualidade, proporcionando que os estudantes da educação básica se apropriem dos resultados da história para a construção de suas próprias elaborações.

Porém, antes que seja possível um debate crítico sobre cultura e arte no espaço escolar, é imperativo que as elaborações acima elencadas como basilares sejam ofertadas durante a formação dos futuros professores. Sendo que, a partir disso, se elaborem políticas públicas nas áreas de educação, arte e cultura em que os atores sociais estejam envolvidos.

O maior desafio para o debate acerca da cultura é a criação de espaços questionadores e contra hegemônicos dentro dos espaços formais de ensino, como nas outras esferas educativas, que possibilitem a apropriação artística, considerando soluções a serem elaboradas, levando em conta não apenas as particularidades das comunidades envolvidas, mas as dificuldades encontradas no ensino formal da sociedade capitalista.

\section{REFERÊNCIAS}

BELLAN, C. C. O ensino de arte para além do boi-bumbá: desmistificando a função da arte no município de Parintins - AM. In: V Encontro Brasileiro de Educação e Marxismo, 2011, Florianópolis. Programação e Resumos e Anais em CD Rom do V EBEM. Florianópolis: NUP Núcleo de Publicações UFSC, 2011.

DUARTE, Newton. Sociedade do conhecimento ou sociedade das ilusões?; quatro ensaios crítico- 


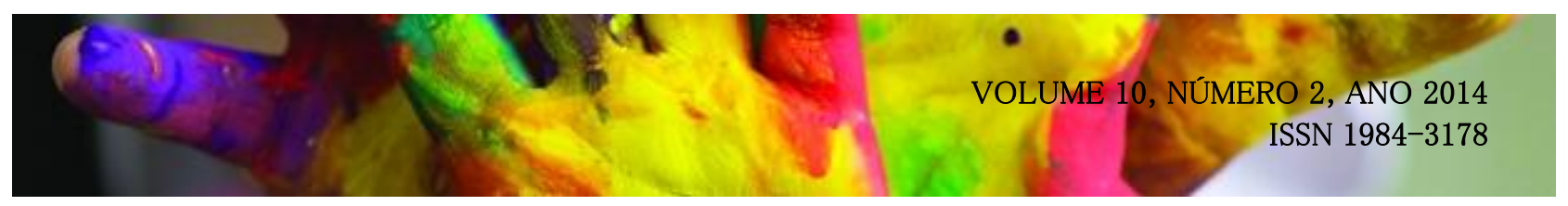

dialéticos em filosofia da educação. Campinas: Autores Associados, 2003.

EAGLETON, Terry. A ideia de cultura. São Paulo: Editora Unesp, 2011.

FOLHA DE SÃO PAULO. Pichador morre após cair de prédio no Centro de São Paulo. Disponível em http://www1.folha.uol.com.br/cotidiano/2014/11/1551415-pichador-morre-aposcair-de-predio-no-centro-de-sao-paulo.shtml._Acesso em 15 de novembro de 2014.

FONSECA DA SILVA, Maria Cristina da Rosa. Formação docente em arte: da formação nas Licenciaturas à formação continuada. Revista Digital Art\& (São Paulo. Online), v. 14, p. 01-24, 2013.

JAMESON, Frederic. Pós-Modernismo. A lógica cultural do capitalismo tardio. São Paulo: Ática, 1996.

UNIVERSIDADE FEDERAL DO AMAZONAS. Projeto Pedagógico do Curso de Licenciatura em Artes Visuais- ICSEZ/UFAM. Parintins, 2013.

REIS, Ronaldo Rosas. O fetiche-cinema contra o cinema- utopia. Cinema Mercadoria, reificação e resistência. Disponível em: <

http://www.unicamp.br/cemarx/anais_v_coloquio_arquivos/arquivos/comunicacoes/gt6/sessao3/Ro naldo_reis.pdf>. Acesso em 15 de novembro de 2014.

RODRIGUES, Lucas. Vítima de racismo, professora vai expor artigo sobre funk nos EUA. Disponível em: < http://educacao.uol.com.br/noticias/2014/08/09/vitima-de-racismo-professoravai-expor-artigo-sobre-funk-nos-eua.htm\#comentarios> Acesso em 15 de novembro de 2014.

SILVA, Jaqueline Conceição. Só mina cruel: Algumas reflexões sobre gênero e cultura afirmativa no universo juvenil do funk. Disponível em: <

http://www.inscricoes.fmb.unesp.br/publicacao.asp?codTrabalho=Nzk2Ng==> Acesso em 15 de novembro de 2014.

WILLIAMS, Raymond. Cultura e materialismo. São Paulo: Editora Unesp, 2011.

VIGOTSKI, L. S. Imaginação e criação na infância. São Paulo: Ática, 2009. 